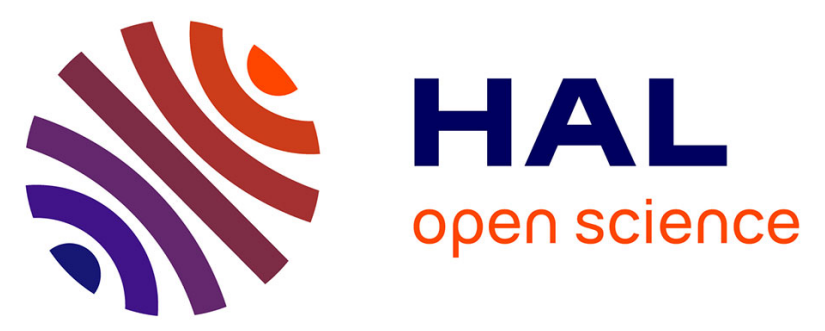

\title{
Age Dependence of Human Exposure in Emerging 5G Bands: Comparison between Plane-Wave Exposure and Multi-Beam Antennas
}

Giulia Sacco, Denys Nikolayev, Ronan Sauleau, Maxim Zhadobov

\section{- To cite this version:}

Giulia Sacco, Denys Nikolayev, Ronan Sauleau, Maxim Zhadobov. Age Dependence of Human Exposure in Emerging 5G Bands: Comparison between Plane-Wave Exposure and Multi-Beam Antennas. 2021 XXXIVth General Assembly and Scientific Symposium of the International Union of Radio Science (URSI GASS), Aug 2021, Rome, France. pp.1-4, 10.23919/URSIGASS51995.2021.9560230 . hal-03388920

\author{
HAL Id: hal-03388920 \\ https://hal.science/hal-03388920
}

Submitted on 20 Oct 2021

HAL is a multi-disciplinary open access archive for the deposit and dissemination of scientific research documents, whether they are published or not. The documents may come from teaching and research institutions in France or abroad, or from public or private research centers.
L'archive ouverte pluridisciplinaire HAL, est destinée au dépôt et à la diffusion de documents scientifiques de niveau recherche, publiés ou non, émanant des établissements d'enseignement et de recherche français ou étrangers, des laboratoires publics ou privés. 


\title{
Age Dependence of Human Exposure in Emerging 5G Bands: Comparison between Plane-Wave Exposure and Multi-Beam Antennas
}

\author{
G. Sacco*(1) D. Nikolayev ${ }^{(1)}$, R. Sauleau ${ }^{(1)}$, and M. Zhadobov ${ }^{(1)}$ \\ (1) Univ Rennes, CNRS, IETR (Institut d'Électronique et des Technologies du numéRique), UMR 6164, F-35000, Rennes, \\ France
}

\begin{abstract}
The fast development of the $5^{\text {th }}$ generation $(5 \mathrm{G})$ mobile networks and human-centered communications is leading to the increasing proliferation of wireless devices resulting in ubiquitous exposure of people of all ages. This study investigates the effect of ageing on the power deposition at $26 \mathrm{GHz}$ and $60 \mathrm{GHz}$, frequencies upcoming for 5/6G. The exposure under near-field conditions induced by multibeam radiating structures is compared to the one induced by a plane wave. The highest variation of the averaged absorbed power density with respect to the typical value for adults is observed at 70 years and corresponds to $8.8 \%$ at $26 \mathrm{GHz}$ and $6.9 \%$ at $60 \mathrm{GHz}$. The maximum decrease is obtained for children at 5 years and is of $-4.5 \%$ at $26 \mathrm{GHz}$ and $-3.7 \%$ at $60 \mathrm{GHz}$. At $26 \mathrm{GHz}$, the plane-wave model results in an underestimation of the averaged power density variations obtained with a multi-beam antenna, while at $60 \mathrm{GHz}$ the variations with the two sources of exposures are almost identical.
\end{abstract}

\section{Introduction}

Dictated by the need for secured communications and high data rates, the frequency bands upcoming for the $5^{\text {th }}$ and future generations of wireless networks are progressively shifting towards the millimeter waves (MMW). With the increasing diffusion of wireless technologies, the number of people using radiating devices is continuously expanding. Tablets and mobile phones are entering in the daily lives of more and more children and seniors, thus requiring an accurate exposure assessment as a function of age. While at lower frequencies this has already been investigated [15], there remains a gap of knowledge on age-dependence at MMW, in particular for realistic sources. The ageing effect was partly discussed considering a normal impinging plane wave [6] but it is still necessary to compare this exposure condition to a scenario considering realistic antennas under near-field conditions.

With the shift towards MMW, due to the higher losses in this frequency range, phased array with multi-beam directive antennas are usually preferred to omnidirectional ones. In addition, many designs proposed in the literature prefer

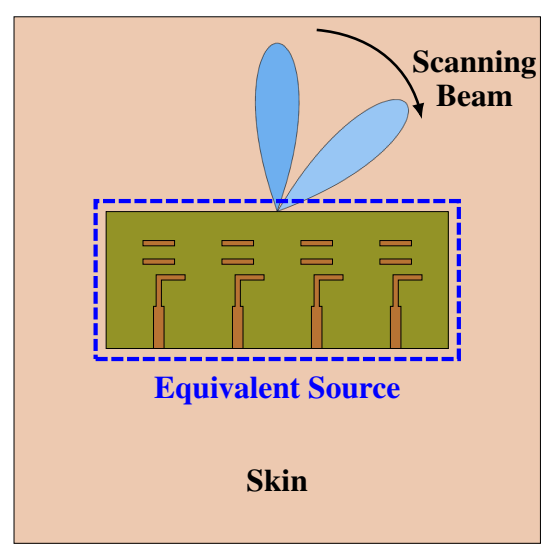

(a)

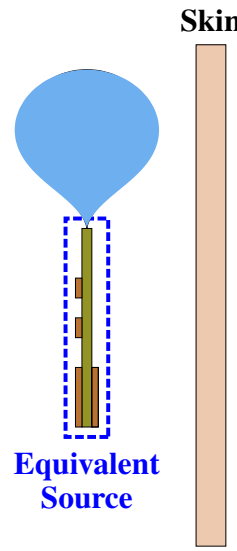

(b)
Figure 1. Exposure scenario: (a) front and (b) lateral view (the dimensions are not to scale).

edge antennas than broadside ones, due to the lower shadowing effect of the user [7-10].

In this paper, we investigate how the exposure varies as a function of age when considering a multi-beam antenna as a source at $26 \mathrm{GHz}$ and $60 \mathrm{GHz}$. These results are then compared to the ones for a plane wave. For the sake of simplicity, since the power absorption mechanism at $26 \mathrm{GHz}$ is similar to the one in the lower part of the MMW spectrum, $26 \mathrm{GHz}$ is referred as MMW.

\section{Materials and Methods}

The considered exposure scenario (Figure 1) is representative of a configuration in which the wireless device is positioned next to the user (e.g., during a phone call).

Two Yagi antennas (one per frequency) inspired from the recent literature works were designed on a RO4350B substrate $\left(\varepsilon_{r}=3.48, \tan \delta=0.0037\right)$ [11]. The chosen substrate thickness is $0.508 \mathrm{~mm}$ at $26 \mathrm{GHz}$ and $0.254 \mathrm{~mm}$ at $60 \mathrm{GHz}$ and the inter-element spacing is $5.77 \mathrm{~mm}$ at $26 \mathrm{GHz}$ and $2.34 \mathrm{~mm}$ at $60 \mathrm{GHz}$. The remaining dimensions are reported in Figure 2. Depending on the phase shift $\alpha$ at the array input ports it is possible to steer the beam. Figure 3 represents the antenna radiation pattern for $\alpha=0^{\circ}$ 


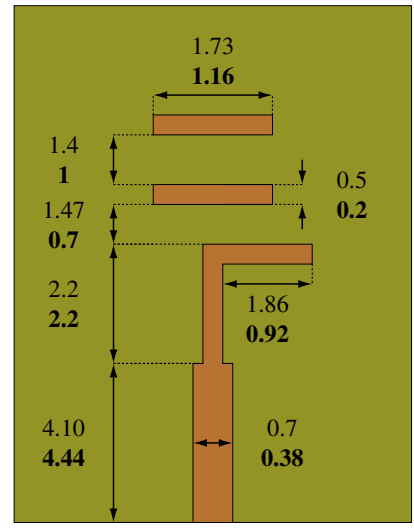

(a)

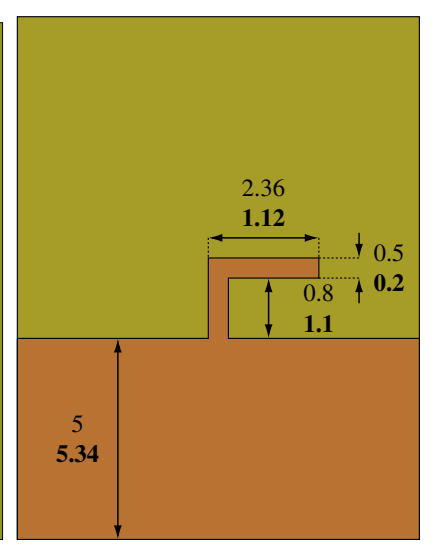

(b)
Figure 2. Yagi antenna geometry: (a) top and (b) bottom. The dimensions (in $\mathrm{mm}$ ) in regular font refer to $26 \mathrm{GHz}$ and the ones in bold to $60 \mathrm{GHz}$.

and $\alpha=142.5^{\circ}$ corresponding to a main beam direction of $0^{\circ}$ and $45^{\circ}$, respectively.

To exclude from the analysis the coupling between the body and the antenna, already discussed in [12], the radiating device is replaced by an equivalent source. The currents on the equivalent source were computed in free space on the box surrounding the 4-element array $(27.33 \times$ $14.02 \times 2.93 \mathrm{~mm}^{3}$ at $26 \mathrm{GHz}$ and $17.05 \times 12.36 \times 1.39 \mathrm{~mm}^{3}$ at $60 \mathrm{GHz}$ ).

To represent the human tissues, a planar skin model $(6 \mathrm{~cm} \times$ $6 \mathrm{~cm} \times 2 \mathrm{~mm}$ at $26 \mathrm{GHz}$ and $4 \mathrm{~cm} \times 4 \mathrm{~cm} \times 1 \mathrm{~mm}$ at $60 \mathrm{GHz}$ ) is used. This approximation is justified by the fact that at these frequencies the typical radius of the body curvature exceeds by five times the penetration depth [13]. The skin complex permittivity computed with the agedependent model reported in [6] at $26 \mathrm{GHz}$ and $60 \mathrm{GHz}$ is represented in Figure 4.

\section{Results}

In the $6-300 \mathrm{GHz}$ range, as suggested by International Commission on Non-ionizing Radiation Protection (ICNIRP) and International Electrical and Electronics Engineers (IEEE) [14,15], the metric used to assess the exposure is the absorbed / epithelial power density

$$
P D_{a v}=\frac{1}{A} \int_{A} \frac{1}{2} \operatorname{Re}\left[\mathbf{E} \times \mathbf{H}^{*}\right] \cdot d \mathbf{s},
$$

where $\mathbf{E}$ and $\mathbf{H}$ are the electric and magnetic fields, respectively, ds is the normal to the surface, and $A=4 \mathrm{~cm}^{2}$ is the averaging area.

In simulations, the distance between the equivalent source and the skin model is set to $0.5 \mathrm{~cm}$, corresponding to typical mobile phone thickness. The variations of the $\mathrm{PD}_{\mathrm{av}}$ as a function of age and in respect to the value for a 35 years old adult [16] are represented in Figure 5.

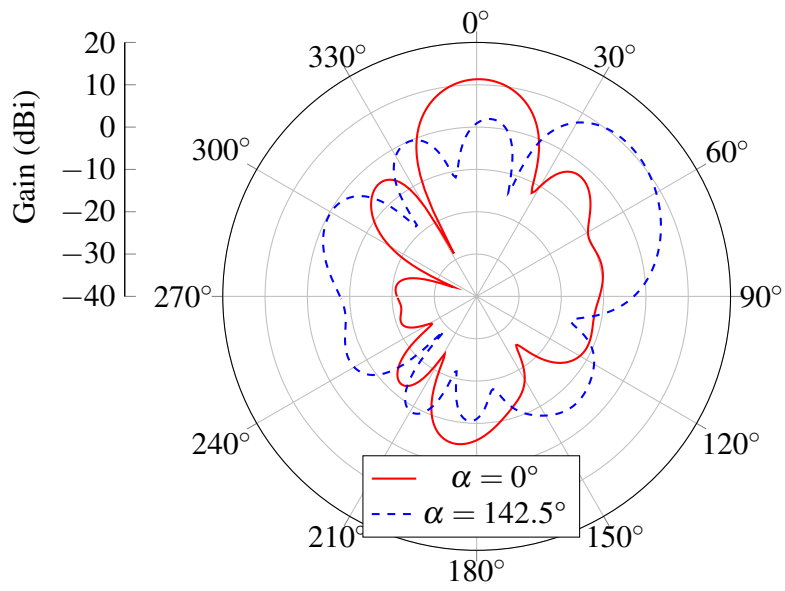

(a)

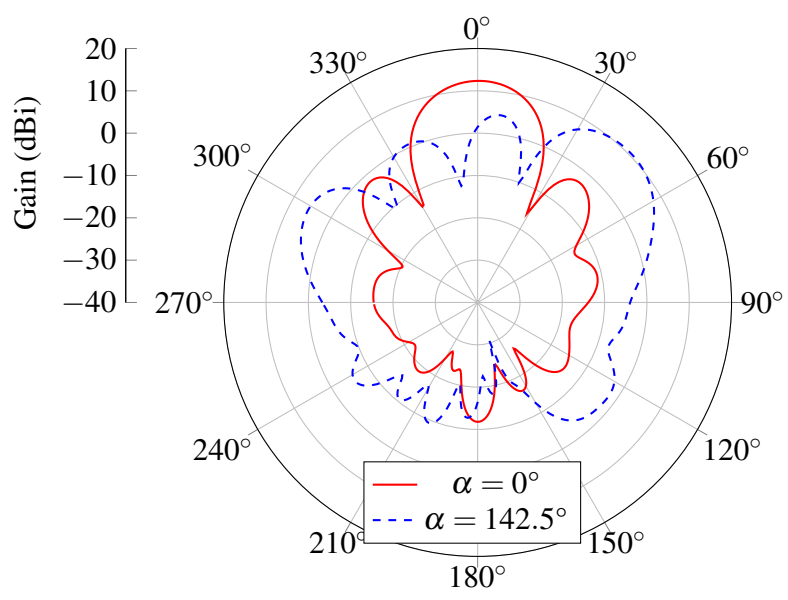

(b)

Figure 3. Radiation patterns (a) at $26 \mathrm{GHz}$ and (b) $60 \mathrm{GHz}$ for $\alpha=0^{\circ}$ and $\alpha=142.5^{\circ}$.

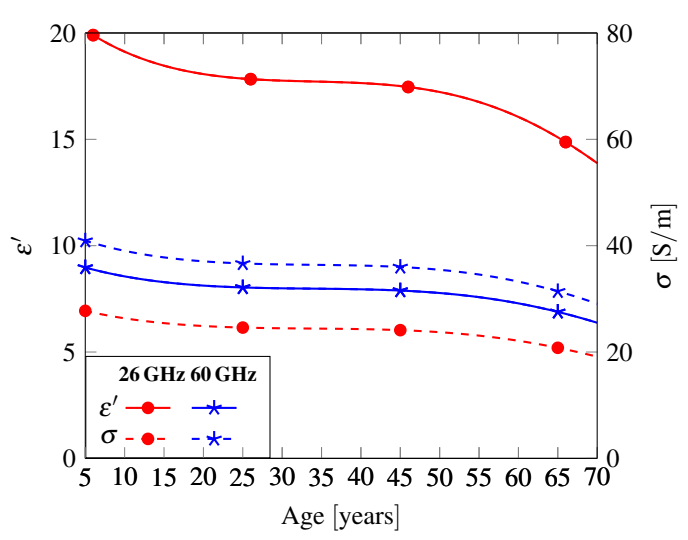

(a)

Figure 4. Permittivity $\varepsilon^{\prime}$, and conductivity $\sigma$ as a function of age at $26 \mathrm{GHz}$ and $60 \mathrm{GHz}$. 


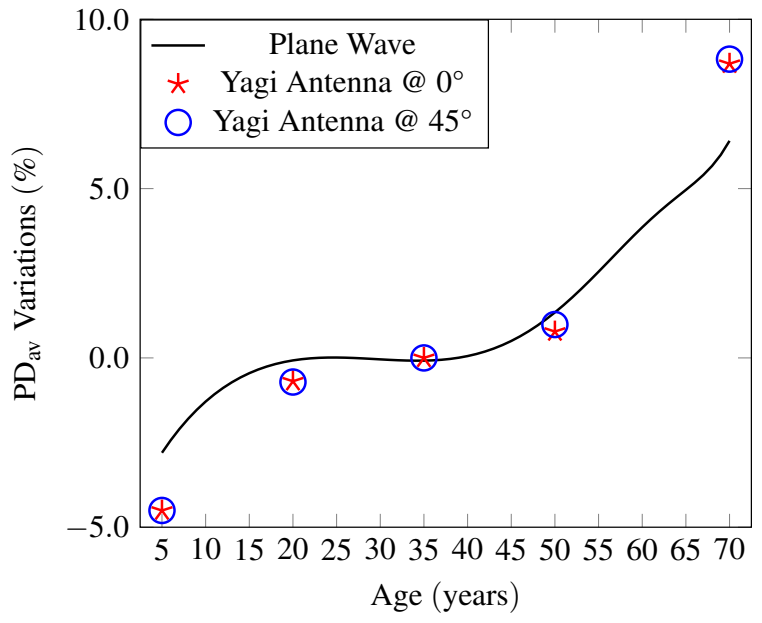

(a)

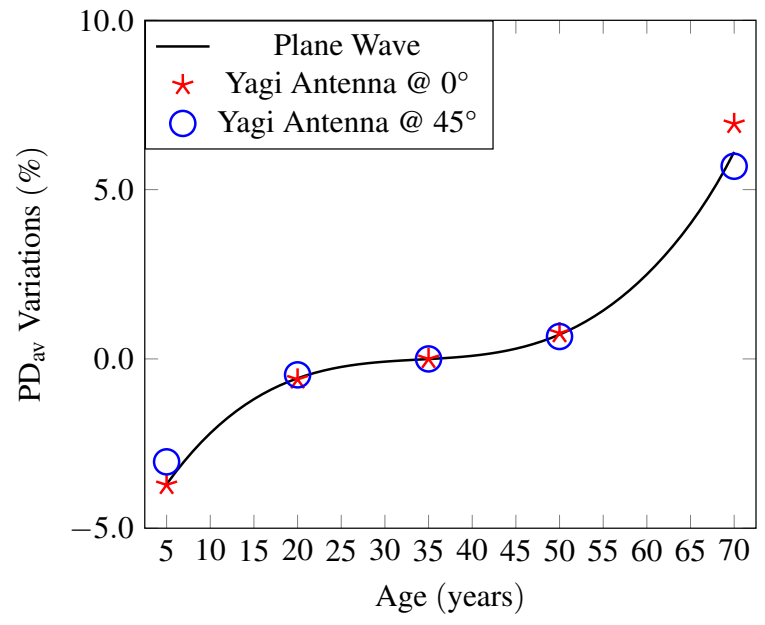

(b)

Figure 5. $\mathrm{PD}_{\mathrm{av}}$ variations as a function of age with respect to the reference value (35 years) at: (a) $26 \mathrm{GHz}$, (b) $60 \mathrm{GHz}$.

$\mathrm{PD}_{\mathrm{av}}$ was computed when considering the Yagi antenna pointing at the broadside $\left(0^{\circ}\right)$ and at $45^{\circ}$. These data are compared with the ones obtained with a plane-wave illumination [6]. Both for the Yagi antenna and plane-wave illumination, the highest increase is observed for seniors (70 years old), while the maximum decrease is for children (5 years old). A plateau is observed between roughly 20 and 50 years. The age-dependent variations can be explained by decrease of the water concentration with age responsible for decrease of the complex permittivity. The lower water concentration for older ages results in reduction of the contrast between skin and air leading to an increase with age of the absorbed power density.

The $\mathrm{PD}_{\mathrm{av}}$ decrease for a 5 years old child is between $-4.5 \%$ (Yagi antenna) and $-2.8 \%$ (plane wave) at $26 \mathrm{GHz}$, while the variations are almost identical for the antenna and the plane wave exposure $(-3$ to $-4 \%)$ at $60 \mathrm{GHz}$. For the 70 years old model, the $\mathrm{PD}_{\mathrm{av}}$ increase is between $6.4 \%$ (plane wave) and $8.8 \%$ (Yagi antenna) at $26 \mathrm{GHz}$ and between $5.7 \%$ to $6.9 \%$ at $60 \mathrm{GHz}$. Note that for all exposure conditions the $\mathrm{PD}_{\mathrm{av}}$ changes are of the same order of magnitude of the typical inter-individual variations (10-15\%).

\section{Conclusion}

This study analyses the effect of ageing on the averaged absorbed power density $\left(\mathrm{PD}_{\mathrm{av}}\right)$ in a skin-equivalent model under near-field exposure conditions. A representative multibeam radiating structure is used as a source at the frequencies upcoming for $5 \mathrm{G}$ and future generations wireless networks $(26 \mathrm{GHz}$ and $60 \mathrm{GHz})$. The results are compared with the ones obtained when considering a normal impinging plane wave as an exposure source.

For all the exposure conditions, $\mathrm{PD}_{\mathrm{av}}$ increases with age. The maximum increase with respect to the reference value at 35 years corresponds to $8.8 \%$ at $26 \mathrm{GHz}$ and $6.9 \%$ at
$60 \mathrm{GHz}$ and is reached for a senior (70 years old). The lowest decrease is at 5 year and is $-4.5 \%$ at $26 \mathrm{GHz}$ and $-3.7 \%$ at $60 \mathrm{GHz}$.

At $26 \mathrm{GHz}$, the results for a plane-wave illumination represent an underestimation of the $\mathrm{PD}_{\mathrm{av}}$ variations. At $60 \mathrm{GHz}$, the variations obtained with a plane wave and a realistic antenna are almost identical. The age-dependent variations are comparable to the typical inter-individual differences and do not exceed the safety margins suggested by the standards and the guidelines (factor of 50 for general public and 10 for occupational exposure).

\section{Acknowledgements}

This work was supported by the French National Research Program for Environmental and Occupational Health of ANSES (2018/2 RF/07) through NEAR 5G project.

\section{References}

[1] J. F. Bakker, M. M. Paulides, A. Christ, N. Kuster, and G. C. van Rhoon, "Assessment of induced SAR in children exposed to electromagnetic plane waves between $10 \mathrm{MHz}$ and 5.6 GHz," Physics in Medicine and Biology, vol. 56, no. 9, pp. 2883-2883, May 2011.

[2] E. Conil, A. Hadjem, F. Lacroux, M. F. Wong, and J. Wiart, "Variability analysis of SAR from $20 \mathrm{MHz}$ to $2.4 \mathrm{GHz}$ for different adult and child models using finite-difference time-domain," Physics in Medicine and Biology, vol. 53, no. 6, pp. 1511-1525, Mar. 2008.

[3] T. Nagaoka and S. Watanabe, "Development of voxel models adjusted to ICRP reference children and their whole-body averaged SARs for whole-body exposure to electromagnetic fields From $10 \mathrm{MHz}$ to $6 \mathrm{GHz}$," IEEE Access, vol. 7, pp. 135 909-135 916, 2019. 
[4] J. Wang, O. Fujiwara, and S. Watanabe, "Approximation of aging effect on dielectric tissue properties for SAR assessment of mobile telephones," IEEE Transactions on Electromagnetic Compatibility, vol. 48, no. 2, pp. 408-413, May 2006.

[5] J. Wiart, A. Hadjem, M. F. Wong, and I. Bloch, "Analysis of RF exposure in the head tissues of children and adults," Physics in Medicine and Biology, vol. 53, no. 13, pp. 3681-3695, Jul. 2008.

[6] G. Sacco, S. Pisa, and M. Zhadobov, "Agedependence of electromagnetic power and heat deposition in near-surface tissues in emerging 5G bands," Scientific Reports, 2020 (In Press).

[7] M. M. Samadi Taheri, A. Abdipour, S. Zhang, and G. F. Pedersen, "Integrated millimeter-wave wideband end-fire 5G beam steerable array and lowfrequency 4G LTE antenna in mobile terminals," IEEE Transactions on Vehicular Technology, vol. 68, no. 4, pp. 4042-4046, Apr. 2019.

[8] Y. Li and K.-M. Luk, "A multibeam end-fire magnetoelectric dipole antenna array for millimeter-wave applications," IEEE Transactions on Antennas and Propagation, vol. 64, no. 7, pp. 2894-2904, Jul. 2016.

[9] V. Raghavan, M.-L. Chi, M. A. Tassoudji, O. H. Koymen, and J. Li, "Antenna placement and performance tradeoffs with hand blockage in millimeter wave systems," IEEE Transactions on Communications, vol. 67, no. 4, pp. 3082-3096, Apr. 2019.

[10] M. F. Khajeim, G. Moradi, R. S. Shirazi, S. Zhang, and G. F. Pedersen, "Wideband vertically polarized antenna with endfire radiation for $5 \mathrm{G}$ mobile phone applications," IEEE Antennas and Wireless Propagation Letters, vol. 19, no. 11, pp. 1948-1952, Nov. 2020.

[11] Rogers Corporation, "RO4000® series high frequency circuit materials," 2018. [Online]. Available: https://rogerscorp. com/-/media/project/rogerscorp/documents/ advanced-connectivity-solutions/english/data-sheets/ ro4000-laminates-ro4003c-and-ro4350b---data-sheet. pdf

[12] M. Ziane, R. Sauleau, and M. Zhadobov, "Antenna/body coupling in the near-field at $60 \mathrm{GHz}$ : Impact on the absorbed power density," Applied Sciences, vol. 10, no. 21, p. 7392, Oct. 2020.

[13] F. S. Barnes and B. Greenebaum, "Handbook of biological effects of electromagnetic fields," Choice Reviews Online, vol. 33, no. 11, pp. 33-6361, Jul. 1996.

[14] International Commission on Non-Ionizing Radiation Protection (ICNIRP), "Guidelines for limiting exposure to electromagnetic fields (100 kHz to $300 \mathrm{GHz})$," Health Physics, vol. 118, no. 5, pp. 483-524, May 2020.
[15] International Electrical and Electronics Engineers (IEEE), "IEEE standard for safety levels with respect to human exposure to electric, magnetic, and electromagnetic fields, $0 \mathrm{~Hz}$ to $300 \mathrm{GHz}, " 2019$.

[16] C. Gabriel, "Compilation of the dielectric properties of body tissues at RF and microwave frequencies." Defense Technical Information Center, Fort Belvoir, VA, Tech. Rep., Jan. 1996. 